\title{
A importância do profissional farmacêutico nos serviços de assistências a saúde da população: execução dos testes de COVID-19 em drogaria
}

The importance of the pharmacist in the population's health care services: carrying out COVID-19 tests in a drugstore

La importancia del farmacéutico en los servicios sanitarios de la población: realización de pruebas de COVID-19 en una droguería

Recebido: 06/12/2021 | Revisado: 12/12/2021 | Aceito: 16/12/2021 | Publicado: 01/01/2022

\author{
Wellington dos Remedios \\ ORCID: https://orcid.org/0000-0002-6945-0996 \\ Faculdade Cosmopolita, Brasil \\ E-mail: remedioswellington0@gmail.com \\ Sandy Medeiros \\ ORCID: https://orcid.org/0000-0002-9393-7673 \\ Faculdade Cosmopolita, Brasil \\ E-mail: Sandy.empreza@gmail.com \\ Margareth Tavares Silva \\ ORCID: https://orcid.org/0000-0001-8136-8162 \\ Faculdade Cosmopolita, Brasil \\ E-mail: margarethfarmaceutica@gmail.com
}

\begin{abstract}
Resumo
Trata-se de uma revisão integrativa da literatura acerca da realização dos testes rápidos (ensaios imunocromatográficos) em drogarias para o auxílio no diagnóstico do COVID-19 e de demais atividades realizadas durante a pandemia, com o intuito de demonstrar quais as contribuições proporcionadas na assistência à saúde da população. A pesquisa foi realizada mediante buscas nas bases de dados da Scielo, PubMed, Lilac, Periodicos Capes e em sites oficiais contendo informações a realização desta atividade, onde vinte e nove artigos (29) foram selecionados para compor os resultados. Observou-se que o farmacêutico na pandemia foi fundamental na realização de ações de promoção à saúde durante a execução dos testes rápidos para COVID-19 e ainda atuando em medidas voltadas à comunicação de formas de segurança e prevenção da disseminação do vírus, além de fornecer orientações para minimizar a prática de automedicação na pandemia.
\end{abstract}

Palavras-chave: COVID-19; Testes sorológicos; Atenção farmacêutica; Serviços farmacêuticos; Promoção da saúde.

\begin{abstract}
This is an integrative review of the literature on the performance of rapid tests (immunochromatographic tests) in drugstores to aid in the diagnosis of COVID-19 and other activities carried out during the pandemic, in order to demonstrate what contributions are provided in assistance to the population health. The research was carried out through searches in the databases of Scielo, PubMed, Lilac, Periodicos Capes and in official websites containing information on this activity, where twenty-nine articles (29) were selected to compose the results. It was observed that the pharmacist in the pandemic was fundamental in carrying out health promotion actions during the execution of rapid tests for COVID-19 and also acting in measures aimed at communicating ways of safety and preventing the spread of the virus, in addition to providing guidelines to minimize the practice of self-medication in the pandemic.
\end{abstract}

Keywords: COVID-19; Serological tests; Pharmaceutical attention; Pharmaceutical services; Health promotion.

\section{Resumen}

Se trata de una revisión integradora de la literatura sobre la realización de pruebas rápidas (pruebas inmunocromatográficas) en farmacias para ayudar en el diagnóstico de COVID-19 y otras actividades realizadas durante la pandemia, con el fin de demostrar qué aportes se brindan en la asistencia a la población. salud. La investigación se realizó mediante búsquedas en las bases de datos de Scielo, PubMed, Lilac, Capas Periódicas y en sitios web oficiales que contienen información sobre esta actividad, donde se seleccionaron veintinueve artículos (29) para componer los resultados. Se observó que el farmacéutico en la pandemia fue fundamental para llevar a cabo acciones de promoción de la salud durante la ejecución de pruebas rápidas para COVID-19 y también actuar en medidas encaminadas a comunicar vías de seguridad y prevenir la propagación del virus, además de brindar pautas para minimizar la práctica de la automedicación en la pandemia.

Palabras clave: COVID-19; Pruebas serológicas; Atención farmacéutica; Servicios farmacéuticos; Promoción de la salud. 


\section{Introdução}

O Coronavírus foi isolado pela primeira vez em 1937 e descrito em 1965, recebendo essa denominação em decorrência do seu perfil na microscopia que se assemelha a uma coroa. Pertence a ordem Nidovirales, família Coronaviridae, é zoonótico e composto de RNA. Os tipos de coronavírus conhecidos até o momento são os alfas coronavírus HCoV-229E e HCoV-NL63, beta coronavírus HCoV-OC43 e HCoV-HKU1, SARS-CoV (causador da síndrome respiratória aguda grave ou SARS), MERS-CoV (responsável pela síndrome respiratória do Oriente Médio ou MERS) e SARS-CoV-2 que provoca a patologia chamada COVID-19, onde os primeiros casos reportados desta doença foram registrados em um mercado de frutos do mar em Wuhan/China descritos como doenças respiratórias desconhecidas (Cavalcante et al., 2020)

A Organização Mundial de Saúde (OMS) recebeu no dia 31 de dezembro de 2019 a notificação sobre tais ocorrências, de que se tratava de uma nova cepa do tipo coronavírus, que rapidamente se alastrou para várias partes do mundo, e no dia 11 de março de 2020 a instituição declarou que a COVID-19 era uma pandemia (Magno et al., 2020). Já no Brasil, a doença foi declarada com Emergência em Saúde Pública de Importância Nacional (ESPIN), havendo a necessidade de estabelecer um plano de gerenciamento com ações voltadas a promoção a saúde da população (Croda \& Garcia, 2020). Dentre as estratégias para enfrentar a disseminação do SARS-CoV-2, o isolamento social e a realização em larga escala de exames, proporcionaram uma maior controle e facilidade na obtenção do diagnóstico da infecção. Atualmente mais de 60 testes são aprovados pela Agência Nacional de Vigilância Sanitária (ANVISA), sendo 38 destes classificados como testes rápidos (Brasil, 2020a).

A importância do teste rápido enquanto estratégia para o combate a pandemia residem no fato de possibilitarem de identificação da doença entre os pacientes de forma rápida, especialmente entre os assintomáticos ou com sintomas não evidentes da covid-19. Continentes como Ásia e Oceania que iniciaram uma abordagem de ampla testagem, associada a medidas de proteção, mostraram resultados satisfatórios no controle da infecção da sua população. Por outro lado, em países da Europa que estabeleceram tardiamente essa metodologia e tiveram resultados diferentes, o número de pacientes acometidos foi bastante expressivo, resultando em sobrecarga dos serviços de saúde, bom uma maior dificuldade de conter a disseminação da COVID-19 (Magno et al., 2020).

O farmacêutico é o profissional qualificado para estar na linha de frente no combate as problemáticas que a pandemia trouxe, onde destaca-se o exercício de suas funções realizadas em drogarias, tendo o papel de fornecer diversos serviços de promoção à saúde no âmbito de suas atividades diárias (Strand, 2020). Neste cenário, o profissional deste segmento teve que se adequar em virtude da emergência de saúde pública internacional relacionada ao SARS-CoV-2, onde ficou autorizado em caráter temporário e excepcional, a utilização de "testes rápidos" (ensaios imunocromatográficos), sem fins de diagnóstico confirmatório, em farmácias com licença sanitária e autorização de funcionamento mediante a publicação da $\operatorname{RDC}^{\circ} 377$, de 28 de abril de 2020 (Brasil, 2020b).

Essa estratégia recebeu bastante notoriedade devido ao fato de que em muitas comunidades o farmacêutico acaba sendo o profissional de saúde mais acessível, sendo por vezes as drogarias um dos primeiros locais de contato do paciente com o sistema de saúde (Hedima, Adeyemi, Ikunaiye, 2020). Ao implantar a realização de testes rápidos nos estabelecimentos, os mesmos precisaram seguir critérios que estabelecessem tanto a segurança do profissional responsável pela execução dos testes, quanto aos colaboradores e usuários do estabelecimento que passaram utilizar o serviço, de maneira a estabelecer um ambiente mais seguro, evitando possíveis riscos de infecção pelo covid-19 (Brasil, 2020b; Brasil, 2021).

A realização de testes rápidos deve seguir critérios quanto a execução, os quais necessitam de alguns aspectos específicos, conforme descrito na legislação vigente (Brasil, 2020b; Brasil, 2021). O presente estudo, teve como intuito realizar uma revisão bibliográfica, pontuando a contribuição do farmacêutico no cenário da pandemia, na execução dos testes rápidos para COVID-19 realizados em drogarias. 


\section{Metodologia}

Trata-se de uma revisão integrativa da literatura, uma vez que o intuito de sintetizar informações acerca da temática proposta, de forma sistemática, ordenada e abrangente (Ercole, Melo \& Alcoforado, 2014). As buscas foram feitas nas seguintes bases de dados: SciELO, PubMed, Lilacs, Portal de Periódicos capes e informações do web site oficial do ministério da saúde (MS). Os critérios de elegibilidade, compreenderam artigos originais publicados em revistas científicas nos idiomas inglês, português e espanhol, com recorte temporal dos último 6 anos (2015-2021). Publicações diretamente relacionadas a propostas do título principal também foram consideradas, tais como: atenção farmacêutica, teste rápido para COVID-19, protocolos que envolvem os processos sobre as determinadas regulamentações dispostas no exercício de cada atividade que o farmacêutico executa no âmbito da drogaria e na execução dos testes rápidos.

As estratégias de buscas realizadas, compreenderam as seguintes etapas:

1- Para o início da pesquisa, utilizamos as seguintes palavras-chaves: COVID-19, Sensibilidade teste COVID-19, Atenção farmacêutica, Farmacêutico pandemia, Teste rápido COVID.

2- Buscas detalhadas em sites governamentais para obtenção das informações e estratégias pré-estabelecidas sobre determinadas atividades obrigatórias.

3- Foram achados 367 artigos e a seleção foi realizada de maneira independente por 2 revisores pelos seguintes critérios:

- Análise de título e resumo;

- Tipos de abordagem do tema propostos (área estabelecida, público-alvo e o objetivo);

- Período de publicação não superior a 6 anos.

4- Dos 367 artigos foram obtidos 135 artigos que compreendem 36,7\% do total dos artigos selecionados inicialmente. Para a seleção dos artigos foi utilizado o programa Rayyan for Systematic Reviews.

5- Os critérios para a análise para os 135 artigos selecionados inicialmente foram reformulados e foram estabelecidas as seguintes determinações:

- Os artigos foram revisto por um terceiro revisor com o intuito de estabelecer uma melhor avaliação do objetivo principal;

- Os artigos foram avaliados na integra;

- Os artigos selecionados deveriam estabelecer uma concordância sobre com a atuação do farmacêutico no exercício das atividades exercidas em drogarias;

- Artigos com a atuação do profissional farmacêutico no atual cenário da pandemia no âmbito da drogaria;

- Artigos que abordam a realidade da execução dos testes rápidos em drogaria;

- Artigos que demonstram à atuação do profissional farmacêutico na contribuição a população com as informações aos cuidados durante a pandemia entre outros fatores que exerçam uma condição de auxílio e contribuição perante a atividade do farmacêutico no atendimento.

Dos 135 artigos antes selecionados, foram incluídos 29 artigos (Figura 1). 
Figura 1: Etapas realizadas para obtenção dos artigos consultados.
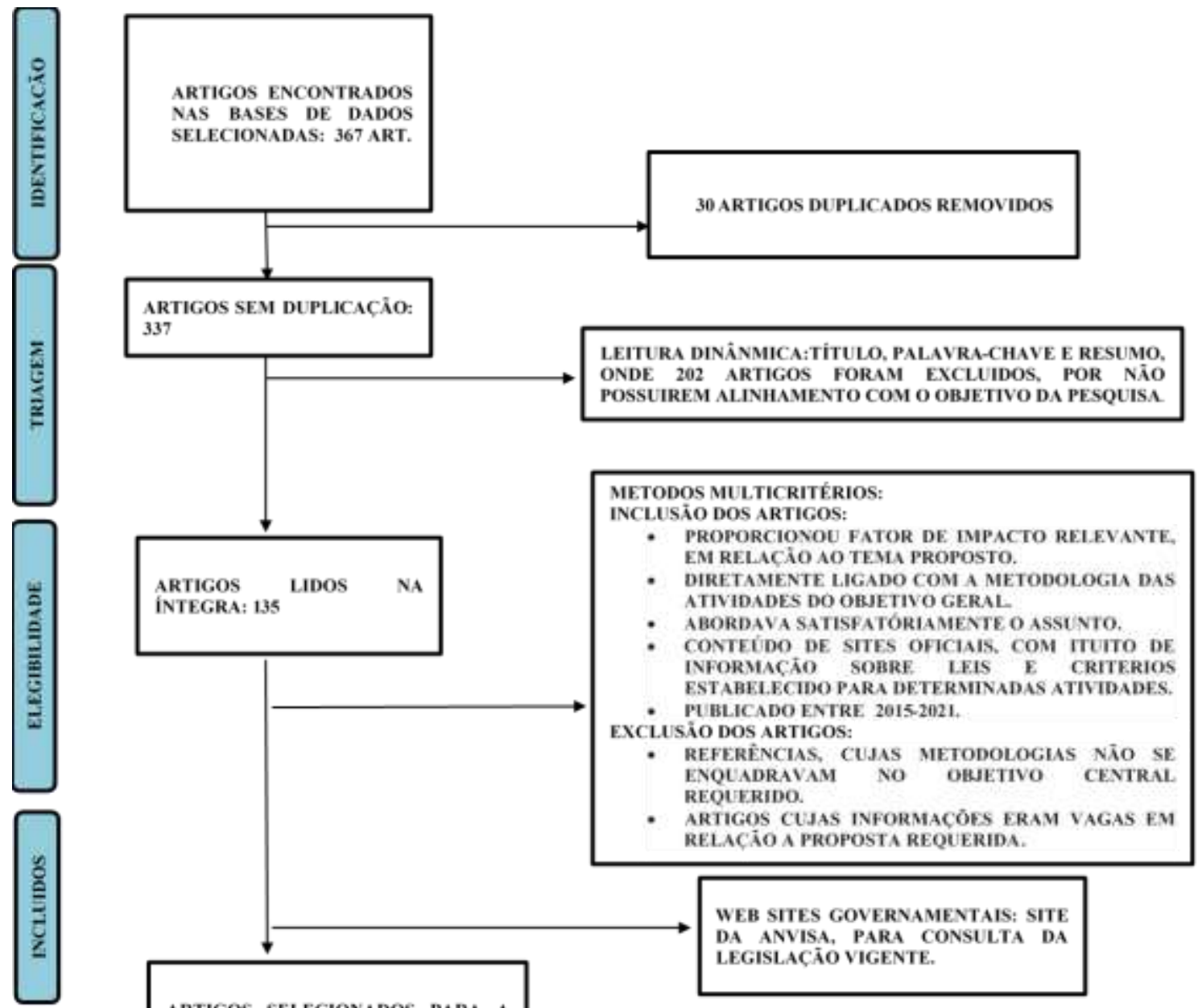

ARTIGOS SELECIONADOS PARA A COMPOSIÇ̃̃O DOS RESULTADOS: 29

Fonte: Autores (2021).

\section{Resultados e Discussão}

Para melhor visualização dos resultados, os artigos selecionados foram organizados em quatro quadros contendo: o título, as abordagens principais, autores e ano de publicação.

Quadro 1: Artigos que abordavam a os testes rápidos.

\begin{tabular}{|c|c|c|}
\hline TÍTULO & ABORDAGEM DOS ARTIGOS & $\begin{array}{l}\text { AUTOR E ANO DE } \\
\text { PUBLICAÇÃO }\end{array}$ \\
\hline $\begin{array}{l}\text { Análise da taxa de eficácia dos testes } \\
\text { sorológicos rápidos para COVID-19 } \\
\text { registrados na ANVISA, uma revisão } \\
\text { sistemática na literatura. }\end{array}$ & $\begin{array}{l}\text {-Desempenho de teste rápido. } \\
\text {--Resultados de eficácia. }\end{array}$ & Santos et al. (2021) \\
\hline $\begin{array}{l}\text { Análise retrospectiva do desempenho do teste } \\
\text { de detecção rápida antigênica Sars-Cov-2 } \\
\text { em comparação com o teste RT-PCR de } \\
\text { referência. }\end{array}$ & $\begin{array}{l}\text {-Desempenho dos RDTs com o RT-PCR cobrindo todos os } \\
\text { processos pré-analíticos, analíticos e pós-analíticos dos dois } \\
\text { exames. } \\
\text {-Integrar a noção de sintomas ao estudo para comparar o } \\
\text { desempenho dos } 2 \text { testes. }\end{array}$ & Bernard et al. (2021) \\
\hline $\begin{array}{c}\text { Avaliação de testes rápidos de antígeno Sars- } \\
\text { Cov-2, Afias COVID-19 Ag e Ichroma } \\
\text { COVID-19 Ag, com amostras seriadas de } \\
\text { nasofaringe de pacientes COVID-19. }\end{array}$ & $\begin{array}{l}\text {-Trabalho voltado para demonstrar a eficiência dos testes } \\
\text { rápidos em comparação ao RT-PCR. }\end{array}$ & Kweon et al. (2021) \\
\hline Comparação de desempenho frente a frente & -Demonstrar que a sensibilidade geral de Panbio com NP & Klein et al. (2021) \\
\hline
\end{tabular}


Research, Society and Development, v. 11, n. 1, e1611124427, 2022

(CC BY 4.0) | ISSN 2525-3409 | DOI: http://dx.doi.org/10.33448/rsd-v11i1.24427

\begin{tabular}{|c|c|c|}
\hline $\begin{array}{l}\text { entre esfregaço nasal auto-coletado e swab } \\
\text { nasofaríngeo coletado por profissional para um } \\
\text { teste de diagnóstico rápido de detecção de } \\
\text { antígeno Sars-Cov-2 listado pela OMS. }\end{array}$ & $(88,9 \%)$ e amostragem NMT $(84,4 \%)$ é comparável. & \\
\hline $\begin{array}{l}\text { Desafios e propostas para ampliação da testagem e } \\
\text { diagnóstico para COVID-19 no Brasil. }\end{array}$ & $\begin{array}{l}\text {-Vantagens do teste rápido. } \\
\text {-Testes como estratégia no combate a pandemia. } \\
\text {-Foco no Brasil. }\end{array}$ & Magno et al., 2020 \\
\hline $\begin{array}{c}\text { Desempenho de testes rápidos de anticorpos } \\
\text { combinados IGM-IGG na vigilância } \\
\text { ocupacional de COVID-19 em empresas } \\
\text { colombianas. }\end{array}$ & $\begin{array}{l}\text {-Trata dos testes rápidos. } \\
\text {-População colombiana. }\end{array}$ & Idrovo et al., 2020 \\
\hline $\begin{array}{l}\text { Diagnóstico COVID-19 - uma revisão dos } \\
\text { métodos atuais. }\end{array}$ & $\begin{array}{c}\text {-Detecção de gene viral pelo método RT-PCR. } \\
\text {-Métodos de detecção de anticorpos. } \\
\text {-Métodos de detecção de antígeno } \\
\text {-Outros métodos. }\end{array}$ & $\begin{array}{l}\text { Yüce, Filiztekin \& Özkaya, } \\
\text { (2020) }\end{array}$ \\
\hline $\begin{array}{c}\text { Ensaio de detecção de antígeno Sars-Cov-2 } \\
\text { rápido em comparação com ensaio RT-PCR } \\
\text { em tempo real para diagnóstico laboratorial de } \\
\text { COVID-19 na Tailândia }\end{array}$ & $\begin{array}{l}\text {-Avalia um teste rápido de detecção de antígeno Sars-Cov- } \\
2 \text { (kit Standard TM Q COVID-19 Ag (SD Biosensor }{ }^{\circledR}, \\
\text { República da Coréia) e faz comparação com o Sars-Cov-2 } \\
\text { RT-PCR para o ensaio de detecção do gene viral, Allplex } \\
\text { TM } 2019 \text {-nCoV Assay (Seegene }{ }^{\circledR} \text {, Coréia). } \\
\text { - O artigo detalha ambos os testes citados acima. } \\
\text {-Fala sobre as características dos casos tailandeses COVID- } \\
19 .\end{array}$ & Chaimayo et al. (2020) \\
\hline $\begin{array}{c}\text { Intervalo de tempo decorrido entre o início dos } \\
\text { sintomas e a realização do exame para } \\
\text { COVID-19 nas capitais brasileiras, agosto de } \\
2020 . \\
\end{array}$ & $\begin{array}{l}\text {-Demonstra a janela imunológica para a realização dos } \\
\text { testes para COVID-19 } \\
\text {-Recomendações de período de testagens. }\end{array}$ & Teixeira et al. (2020) \\
\hline $\begin{array}{l}\text { Prática de farmácia comunitária na itália } \\
\text { durante a pandemia COVID-19 (Sars- } \\
\text { Cov-2): mudanças regulatórias e uma } \\
\text { análise transversal da soroprevalência. }\end{array}$ & $\begin{array}{c}\text {-Acessibilidade ao atendimento. } \\
\text {-Medidas preventivas. } \\
\text {-Testes rápido como medidas de isolamento para conter o } \\
\text { avanço da pandemia, executados em drogarias. } \\
\text {-Foco na Itália. }\end{array}$ & $\begin{array}{c}\text { Baratta Francesca et al. } \\
(2021)\end{array}$ \\
\hline $\begin{array}{l}\text { status atual dos testes de diagnóstico para } \\
\text { infecção por Sars-Cov-2 e } \\
\text { desenvolvimentos futuros: uma revisão. }\end{array}$ & $\begin{array}{l}\text {-Exames laboratoriais precisos e oportunos. } \\
\text {-Políticas e critérios para testes de diagnóstico. } \\
\text {-Teste de sorologia para anticorpos Sars-Cov- } 2 \text {. } \\
\text {-Teste de antígeno para Sars-Cov-2. } \\
\text {-Novas técnicas de detecção de RNA. }\end{array}$ & Gao \& Quan, (2020) \\
\hline $\begin{array}{c}\text { Teste de anticorpos COVID-19 IGG/IGM no } \\
\text { condado de Los Angeles, Califórnia. }\end{array}$ & $\begin{array}{c}\text {-Teste rápido. } \\
\text {-Avaliação da eficácia do teste. } \\
\text {-Foco ao artigo em Los Angeles, Califórnia. } \\
\end{array}$ & Ahmad et al. (2020) \\
\hline $\begin{array}{l}\text { Testes sorológicos no diagnóstico da COVID- } \\
19 .\end{array}$ & $\begin{array}{l}\text {-Contexto da realização do teste. } \\
\text {-Compreensão das respostas imunológicas. }\end{array}$ & Assis et al. (2021) \\
\hline $\begin{array}{c}\text { Validade e confiabilidade dos testes rápidos } \\
\text { imunocromatográficos IGM/IGG para o } \\
\text { diagnóstico salivar de COVID-19. }\end{array}$ & $\begin{array}{l}\text { - Teste rápido COVID-19 IgG / IgM } \\
\text {-Dados dos resultados de eficiência dos testes } \\
\text { demonstrados. }\end{array}$ & Vilela et al. (2021) \\
\hline
\end{tabular}

Fonte: Autores (2021).

Quadro 2: Artigos que abordavam as atividades do farmacêutico em drogarias auxiliando no enfrentamento da pandemia.

\begin{tabular}{|c|c|c|}
\hline TÍTULO & ABORDAGEM DOS ARTIGOS & $\begin{array}{c}\text { AUTOR E ANO DE } \\
\text { PUBLICAÇÃO }\end{array}$ \\
\hline $\begin{array}{c}\text { Análise da produção científica sobre os } \\
\text { serviços farmacêuticos comunitários no } \\
\text { enfrentamento da pandemia pelo corona } \\
\text { vírus. }\end{array}$ & -Atuação prática da atenção farmacêutica a \\
população. & Prado et al. (2021) \\
\hline $\begin{array}{c}\text { Automedicação no Brasil durante a } \\
\text { pandemia da COVID-19 e o papel do } \\
\text { profissional farmacêutico, uma revisão } \\
\text { sistemática. }\end{array}$ & $\begin{array}{c}\text { Os riscos da automedicação na pandemia. } \\
\text {-O farmacêutico como responsável de esclarecer a } \\
\text { respeito dos medicamentos utilizados para tratar a } \\
\text { COVID-19 divulgados. }\end{array}$ & Oliveira et al. (2021) \\
\hline
\end{tabular}




\begin{tabular}{|c|c|c|}
\hline $\begin{array}{c}\text { Contribuição dos farmacêuticos } \\
\text { comunitários para o gerenciamento } \\
\text { de doenças durante a pandemia de } \\
\text { COVID- } 19 .\end{array}$ & $\begin{array}{l}\text {-Relata a rotina da perspectiva das atividades } \\
\text { desenvolvidas. } \\
\text {-Destaca a importância da farmácia comunitária na } \\
\text { dinâmica da pandemia. } \\
\text {-Foco nos Estados Unidos. }\end{array}$ & $\underline{\text { Strand et al. (2020) }}$ \\
\hline $\begin{array}{c}\text { COVID - 19: cuidados farmacêuticos } \\
\text { durante a pandemia }\end{array}$ & $\begin{array}{c}\text {-Papel do farmacêutico no controle da transmissão. } \\
\text {-Atenção às necessidades da comunidade durante a } \\
\text { crise. } \\
\text { - Disseminação de informações sobre a doença. } \\
\text {-Monitoramento de reações advindas do uso de } \\
\text { medicamentos. }\end{array}$ & $\begin{array}{l}\text { Cagnazzo \& Chiari- } \\
\text { Andreo, (2020) }\end{array}$ \\
\hline $\begin{array}{c}\text { O papel ativo do farmacêutico no } \\
\text { combate à desinformação de } \\
\text { medicamentos COVID-19. }\end{array}$ & $\begin{array}{l}\text {-Farmacêutico no combate a desinformação na } \\
\text { pandemia. }\end{array}$ & Marwitz (2020) \\
\hline $\begin{array}{l}\text { O papel do farmacêutico na pandemia de } \\
\text { COVID-19: Revisão integrativa. }\end{array}$ & $\begin{array}{l}\text {-Farmacêutico no combate a desinformação. } \\
\text {-Acessibilidade a tratamento paliativo dos sintomas } \\
\text { do COVID-19. } \\
\text {-Orientações farmacêuticas sobre medidas sobre } \\
\text { medidas de prevenção e cuidados na pandemia. }\end{array}$ & $\begin{array}{l}\text { Passos, Castoldi \& Soler, } \\
\text { (2021.) }\end{array}$ \\
\hline $\begin{array}{l}\text { Preparação dos farmacêuticos para } \\
\text { responder à emergência da } \\
\text { pandemia COVID-19 no Brasil: } \\
\text { um panorama abrangente. }\end{array}$ & $\begin{array}{l}\text {-Artigo demonstra os requisitos mais ativos no } \\
\text { período da pandemia nas drogarias, ressaltando a } \\
\text { atenção farmacêutica. } \\
\text {-Foco no Brasil. }\end{array}$ & Martins et al. (2020) \\
\hline $\begin{array}{l}\text { Surto de Sars-Cov-2: como os } \\
\quad \text { farmacêuticos podem ajudar? }\end{array}$ & $\begin{array}{c}\text {-Farmacêutico atuando em conscientizar a população } \\
\text { nos aspectos gerais voltado a pandemia. } \\
\text {-Informação a medidas de prevenção } \\
\text {-Gerenciamento de sintomas leves } \\
\text {-Identificação de problemas farmacológicos. }\end{array}$ & $\begin{array}{l}\text { Al-Quteimat \& Amer, } \\
\text { (2020) }\end{array}$ \\
\hline
\end{tabular}

Fonte: Autores (2021).

Quadro 3: Artigos complementares sobre o vírus da COVID-19, medidas de controle e resultados sobre a pandemia.

\begin{tabular}{|c|c|c|}
\hline TÍTULO & ABORDAGEM DOS ARTIGOS & $\begin{array}{l}\text { AUTOR E ANO DE } \\
\text { PUBLICAÇÃO }\end{array}$ \\
\hline $\begin{array}{c}\text { COVID-19 no Brasil: evolução da epidemia } \\
\text { até a semana epidemiológica } 20 \text { de } \\
2020 . \\
\end{array}$ & $\begin{array}{c}\text {-Relata a doença causada pelo novo } \\
\text { coronavírus em diferentes países, destacando } \\
\text { o seu crescimento de infecção. }\end{array}$ & Cavalcante et al. (2020) \\
\hline $\begin{array}{c}\text { Infodemia: excesso de quantidade em } \\
\text { detrimento da qualidade das } \\
\text { informações sobre a COVID-19. }\end{array}$ & $\begin{array}{l}\text {-Estabelece um conceito de tipo de } \\
\text { informação. } \\
\text {-Informações sem fundamentos científicos } \\
\text { ou de caráter comprovado. }\end{array}$ & Garcia \& Duarte, (2020) \\
\hline $\begin{array}{c}\text { Resposta imediata da vigilância em saúde à } \\
\text { epidemia da COVID-19. }\end{array}$ & $\begin{array}{l}\text {-Artigo voltado para ações e resposta da } \\
\text { ANVISA ao combate a pandemia. }\end{array}$ & Croda \& Garcia (2020) \\
\hline $\begin{array}{c}\text { Respostas imunes humorais e anticorpos } \\
\text { neutralizantes contra Sars-Cov- } \\
\text { 2: implicações na patogênese e } \\
\text { imunidade protetora. }\end{array}$ & $\begin{array}{l}\text {-Relata as respostas imunológicas após o } \\
\text { contato com o vírus da COVID-19. }\end{array}$ & Carrillo et al. (2020) \\
\hline
\end{tabular}


Quadro 4: Artigos que versavam sobre a percepção e satisfação da população ou do próprio farmacêutico quanto a atuação deste profissional no combate à pandemia.

\begin{tabular}{|c|c|c|}
\hline TíTULO & ABORDAGEM DOS ARTIGOS & AUTOR E ANO DE PUBLICAÇÃO \\
\hline $\begin{array}{c}\text { Percepção da população sobre o papel } \\
\text { do Farmacêutico no contexto da } \\
\text { pandemia do novo coronavírus. }\end{array}$ & $\begin{array}{c}\text {-Abordagem do reconhecimento do } \\
\text { farmacêutico sobre as atividades } \\
\text { desenvolvidas na pandemia, relatadas } \\
\text { pela população da pesquisa realizada. }\end{array}$ & Lacerda, Sampaio \& Dourado, (2021) \\
\hline $\begin{array}{c}\text { Resposta dos farmacêuticos durante uma } \\
\text { pandemia: uma pesquisa sobre a } \\
\text { prontidão para fazer o teste durante } \\
\text { o COVID-19. }\end{array}$ & $\begin{array}{c}\text {-Artigo voltado para saber a opinião dos } \\
\text { farmacêuticos sobre a realização dos } \\
\text { testes COVID-19. }\end{array}$ & Uebbing et al. (2020) \\
\hline $\begin{array}{c}\text { Vontade dos farmacêuticos em fornecer } \\
\text { serviços para a doença por } \\
\text { coronavírus (COVID-19) e as } \\
\text { necessidades de apoio aos testes, } \\
\text { gestão e prevenção do COVID-19. }\end{array}$ & $\begin{array}{c}\text {-Pesquisa de campo, com intuito de } \\
\text { abordar a vontade do farmacêutico na } \\
\text { realização do teste para COVID-19 } \\
\text {-Aborda uma proposta do exercício da } \\
\text { função em farmácias. }\end{array}$ & Nguyen et al. (2020) \\
\hline
\end{tabular}

Fonte: Autores (2021).

\section{Farmacêutico na pandemia}

Os farmacêuticos que atuam no seguimento de drogarias em sua rotina estão aptos para desenvolver as seguintes atividades: abastecimento, conservação, controle de qualidade, segurança, eficácia terapêutica, acompanhamento, avaliação da utilização, obtenção e difusão dos profissionais de saúde, do paciente e da comunidade para assegurar o uso racional de medicamentos (Merola, El-Khatib \& Granjeiro, 2005). Estão a postos para fornecer respostas concretas no combate à pandemia, onde mantiveram os serviços essenciais a comunidade e incluíram os novos serviços destinados a população no tocante a prestação de informações e demais ações prioritárias que visam a proteção da saúde (Strand et al., 2020). Um estudo realizado com informações de diversos países, abordando os serviços de farmácia onde o protagonista é o farmacêutico, sobre as atividades que envolve a profissão no atual cenário, destacou dentre eles que o profissional atua principalmente de maneira a estabelecer as informações medidas de segurança, higiene e as medidas de distanciamento social para o público de maneira a promover o combate a desinformação (Passos, Castoldi \& Soler, 2021).

As atividades farmacêuticas compreendem a promoção e o uso seguro de medicamentos, principalmente na adesão de medicamentos utilizados para o tratamento de doenças agudas e crônicas (Martins et al., 2020). No cenário da pandemia, associado a grande repercussão da mídia ou diversos meios de informações, ocorre a chamada "infodemia" que significa "um grande aumento no volume de informações associadas a um assunto específico, que podem se multiplicar exponencialmente em pouco tempo devido a um evento específico. Nessa situação, surgem rumores e desinformação, além da manipulação de dados com intenção duvidosa. Na era da informação, esse fenômeno é amplificado pelas redes sociais e se alastra mais rapidamente, como um "vírus" (Garcia \& Duarte, 2020). Diversos autores destacam que a "infodemia" está muito presente e que o farmacêutico tem total competência para combater esse excesso de desinformação, orientando a população de diferentes formas, com bases cientificas comprovadas para auxiliar as pessoas, trazendo para elas a realidade dos fatos, contribuindo com a segurança da população (Assis et al., 2021; Marwitz, 2020; Passos, Castoldi, \& Soler, 2021; Prado et al., 2021).

Uma pesquisa onde avaliaram-se as atividades desenvolvidas pelo profissional farmacêutico no período da pandemia, de acordo com a percepção da população, obteve resultados significativos e de mérito aos farmacêuticos, onde a maioria das pessoas avaliadas considerou o farmacêutico como profissional atuante na linha de frente da pandemia (Lacerda, Sampaio \& Dourado, 2021). Em meio aos serviços prestados em drogarias, destaca-se um dos mais importantes na perspectiva de 
combater a pandemia, tais como os serviços de testagem rápida da comunidade, no intuito de diminuir a sobrecarga dos serviços e ainda durante o atendimento ao paciente, elaborando possíveis fluxogramas de sinais e sintomas para tomadas de decisões capazes de minimizar os impactos da doença (Prado et al., 2021).

A realização dos testes rápidos para COVID-19 representa uma categoria nova de serviços estabelecida em drogarias. Um levantamento foi executado com intuito de investigar a opinião dos farmacêuticos a respeito da resposta do profissional na realização dos testes rápidos, por meio de questionários em diferentes plataformas. Os resultados mostraram que a maioria, cerca de $(99,9 \%)$ dos cento e vinte dois farmacêuticos entrevistados se propuserem a realizar os testes se estivessem devidamente protegidos, sendo as preocupações a respeito da falta de equipamentos de proteção individual (EPIs) um dos fatores que geravam receio entre os profissionais, pois uma vez infectados poderiam levar a infecção a familiares (Uebbing et al., 2020). Houve ainda relatos de dificuldades a nível de retorno de pagamento pela execução dos testes, que foram apenas inclusos na sua grade de tarefas ou sem retorno financeiro satisfatório, mostrando que apesar da importância da atuação deste profissional, o reconhecimento dessa importância ainda não recebe o devido retorno (Uebbing et al., 2020).

Por outro lado, Nguyen et al. (2020) observaram em seu trabalho que apenas $50 \%$ dos duzentos e vinte e nove dos farmacêuticos entrevistados optava por atuar na realização dos testes rápidos para COVID-19, sendo um dos maiores impasses seria a falta do reconhecimento financeiro pela realização dos testes, onde não tinham um valor pago pela execução da atividade. Por fim, um estudo acerca da adesão do farmacêutico as normas de boas práticas de higiene com intuito de manter a segurança na realização dos testes rápidos, uma pequena parte dos profissionais relatou que deixaram de realizar algumas práticas de higiene e se contaminaram com o vírus da COVID-19, enquanto os que afirmara seguir as recomendações obtiveram sucesso na não contaminação (Baratta et al., 2021). Tal fato denota que mesmo entre profissionais de saúde, a adesão a práticas de biossegurança pode ser incompleta, necessitando de ações de conscientização dentro deste público.

\section{Sobre os testes}

A pandemia trouxe para a sociedade cientifica um grande desafio, onde houve a necessidade da elaboração de estratégias de forma aceleradas para conter o avanço da pandemia, dentre elas a realização de uma ampla testagem, visando o diagnóstico como medida preventiva (Magno et al., 2020). Os testes rápidos são ensaios imunocromatográficos, que passaram a ser realizados no Brasil em drogarias durante a pandemia, conforme estabelecido pela RDC n⿳ 377 , de 28 de abril de 2020 , que autorizou a realização dos testes como de triagem para o diagnóstico do COVID-19. Para serem utilizados, os testes rápidos para a pesquisa de anticorpos ou antígeno do novo coronavírus devem possuir registro na ANVISA, atualmente estão aprovados cerca 64 testes para COVID-19, sendo destes 38 testes imunocromatográficos (testes rápidos) (BRASIL, 2020a).

A ANVISA disponibiliza a relação de todos os testes disponíveis para a realização da testagem para COVID-19, incluindo as informações correspondentes aos detalhe do produto, tais como: nome do fabricante, CNPJ do mesmo, número de autorização e nome do produto, apresentação dos componentes do kit, rotulagem, manual de instrução do uso adequado do kit, nome técnico, registro do produto, processo (relacionado a aprovação do produto), fabricante legal, classificação de risco e o vencimento de seu registro. Tais dados tem objetivam demonstrar de forma clara o que está sendo disponibilizado para o uso da população (Brasil, 2020a).

Para sua execução os testes rápidos não necessitam de uma orientação médica prévia, mas é necessário que o farmacêutico faça a análise da situação para a melhor escolha de abordagem para os testes, onde a farmácia em que seja realizado o teste deve obedecer às normas estabelecidas pelo fabricante. Dentre os EPIs necessários para a coleta das amostras dos pacientes, o farmacêutico deve utilizar avental, óculos de proteção, touca, luvas descartáveis e máscaras cirúrgicas, não sendo possível a compra do teste para a realização em domicílio (CRF-SP, 2020). Os testes rápidos para a COVID-19 trazem como vantagens a facilidade de execução de uma rápida resposta dos resultados, contudo, vale ressaltar que a taxa de eficácia é 
variável de acordo com o fabricante (Santos et al., 2021). Estes testes que detectam antígeno e anticorpo possuem características distintas sobre a perspectiva de tempo de coleta, onde estudos mostram que o período adequado do antígeno varia entre 2 e 7 dias, já a coleta do anticorpo seria no período maior que 8 dias (Teixeira et al., 2020).

Kweon et al., (2021) avaliaram 2 tipos de testes rápido para antígeno, onde as amostras foram confirmadas por testes moleculares anteriormente. Os autores relataram que os níveis da carga viral auxiliam para o aumento da especificidade e sensibilidades dos testes rápidos (Kweon et al., 2021). Outra pesquisa realizada mostrou resultados satisfatórios de testes rápidos em relação ao teste de reação de transcriptase reversa seguida de reação em cadeia da polimerase (RT-PCR), onde a sensibilidade e especificidade se mostraram próxima aos resultados do teste molecular, destacando seu potencial na detecção do antígeno SARS-CoV-2 como um ensaio de triagem (Chaimayo et al., 2020).

Os testes rápidos de anticorpo têm a capacidade de medir os níveis de IgG e IgM em amostras de sangue, soro ou plasma, necessitando necessariamente da resposta do organismo, com capacidade para uma ampla triagem em situação de pandemia (Yüce, Filiztekin \& Özkaya, 2020), sendo ensaios de natureza puramente qualitativa para indicar a presença ou ausência de anticorpos contra o SARS-CoV-2 (ASSIS et al., 2021). Bernard et al., (2021) realizaram um estudo onde o desempenho de testes rápidos comparado a RT-PCR foi avaliado, utilizando amostras coletadas de pessoas com sintomas iniciais no período de 24 horas. Os autores observaram que a sensibilidade dos testes rápidos em comparação a todos os testes RT-PCR foi de $56 \%$ e que sua sensibilidade diminui muito rapidamente uma vez manifestados os sintomas, diferente da carga viral estimada no teste molecular.

$\mathrm{O}$ ato de realização dos testes segue normas especificas de cada fabricante, quanto ao tipo de amostra, técnicas de utilização, tempo de espera etc. Porém, o conhecimento do farmacêutico traz o diferencial na avaliação previa à realização da testagem, onde é analisado o estado do paciente para definir o teste de acordo com a janela imunológica (Larissa et al., 2021). Gao \& Quan (2020) destacam que os dados obtidos devem ser interpretados com cautela, uma vez que estão fortemente ligados a fatores como carga viral e a taxa de replicação do vírus, além da possibilidade de detecção cruzada de anticorpos de outros tipos coronavírus e o fato de que muitos testes de antígenos possuem uma sensibilidade baixa quando comparada ao RT-PCR, o que por sua vez, pode resultar em falsos negativos.

\section{Considerações Finais}

Os achados sobre a atuação do farmacêutico em drogarias se mostraram muito promissores, pois relatam que as atividades prestadas perante a população tiveram a capacidade de suprir uma necessidade tanto a respeito de orientação, medicamentos e até mesmo a realização de testes rápido para COVID-19. O farmacêutico compreende ser atuante nos seguimento de medidas de prevenção do ambiente de trabalho e população ao novo coronavírus, no controle da automedicação mediante dialogo capaz de esclarecer dúvidas e combater as "infodemias". A realização dos testes rápidos pelo profissional farmacêutico detém uma grande importância no cenário atual, onde o profissional entende os limites de detecção de tais testes e sua relação com a janela imunológica, para uma melhor escolha do método de diagnóstico e orientação do paciente. Este profissional pode fornecer indicações paliativas sobre a perspectiva de alívio e melhora à população, além de cuidados para a disseminação do vírus.

Em face aos benefícios desta atividade, encontra-se o medo de se contaminar e transmitir a familiares, onde os estudos mostraram que quando o farmacêutico não segue as devidas medidas de segurança já estabelecidas, a chance de infeção aumenta, reforçando a necessidade de utilização dos equipamentos de proteção individual dessas atividades. Por fim, ressaltase o relato de que a realização desta importante função pelos profissionais, apesar de reconhecida pela população como de grande importância, não recebeu o devido reconhecimento financeiro, o que acaba funcionando com um fator que desestimula os profissionais na adesão a esta nova possibilidade. Destacamos aqui a necessidade de levantamentos acerca da prática de 
automedicação na pandemia, bem como suas consequências à população, além de ações realizadas pelos farmacêuticos no combate ao uso irracional de medicamentos, como tentativa de minimizar danos aos usuários. Sabendo que durante a pandemia esse uso foi impulsionado pelas infodemias, tais trabalhos são importantes para visualização de uma das mais importantes atividades do farmacêuticos perante à comunidade, especialmente no âmbito das drogarias, à saber a promoção do uso racional de medicamentos e o combate à desinformação.

\section{Referências}

Ahmad, K., Rezvanizadeh, V., Dahal, S., Kinninger, A., Ghanem, A. K., Lakshmanan, S., Hamal, S., Flores, F., Dailing, C., Roy, S. K., \& Budoff, M. J. (2021). COVID-19 IgG/IgM antibody testing in Los Angeles County, California. European journal of clinical microbiology \& infectious diseases: official publication of the European Society of Clinical Microbiology, 40(2), 457-459. https://doi.org/10.1007/s10096-020-04111-3

Al-Quteimat, O. M., \& Amer, A. M. (2021). SARS-CoV-2 outbreak: How can pharmacists help? Research in social \& administrative pharmacy: RSAP, 17(2), 480-482. https://doi.org/10.1016/j.sapharm.2020.03.018

Assis, L., Souza, T., Aninger, G., \& Moura, A. (2021). Testes sorológicos no diagnóstico da COVID-19. Conexão Ciência (Online), 15(4), 59-69. https://doi.org/10.24862/cco.v15i4.1312

Baratta, F., Visentin, G. M., Ravetto, E.L., Parente, M., Pignata, I., Venuti, F., Di Perri, G., \& Brusa, P. (2021). Community Pharmacy Practice in Italy during the COVID-19 (SARS-CoV-2) Pandemic: Regulatory Changes and a Cross-Sectional Analysis of Seroprevalence. Int J Environ Res Public Health., 18(5), 2302. doi: 10.3390/ijerph18052302.

Bernard, M., Cosentino, G., Pieri, L., Zachary, P., Buser, M., Kbaier, L., \& Giannoli, J. M. (2021). Analyse rétrospective des performances du test de détection rapide antigénique du SARS-CoV-2 comparé au test de référence RT-PCR [Retrospective analysis of the performance of the SARS-CoV-2 rapid antigen detection test compared to the reference RT-PCR test]. Annales de biologie clinique, 79(2), 168-175. https://doi.org/10.1684/abc.2021.1641

Brasil (2020a). Ministério da Saúde-ANVISA: Produtos para saúde-testes de COVID-19. https://consultas.anvisa.gov.br/\#/saude/25351264267202026/?nomeTecnico=coronav\%C3\%ADrus.

Brasil (2020b). Ministério da Saúde-ANVISA. Resolução da diretoria colegiada - RDC no 377, de 28 de abril de 2020. https://www.in.gov.br/web/dou//resolucao-rdc-n-377-de-28-de-abril-de-2020-254429215.

Brasil (2021). Ministério da Saúde - Agência Nacional de Vigilância Sanitária - Anvisa Nota Técnica No 7/2021/SEI/GRECS/GGTES/DIRE1/ANVISA Orientação para a realização de testes rápidos, do tipo ensaios imunocromatográficos, para a investigação da infecção pelo novo coronavírus (SARS-CoV-2). https://www.gov.br/anvisa/pt-br/centraisdeconteudo/publicacoes/servicosdesaude/notas-tecnicas/nota-tecnica-no-7-de-2021.pdf.

Cagnazzo, T. di O., \& Chiari-Andréo, B.G. (2020). COVID - 19: Cuidados farmacêuticos durante a pandemia. Revista Brasileira Multidisciplinar, 23(1), 161178. https://doi.org/10.25061/2527-2675/ReBraM/2020.v23i1.973

Carrillo, J., Izquierdo-Useros, N., Ávila-Nieto, C., Pradenas, E., Clotet, B., \& Blanco, J. (2021). Humoral immune responses and neutralizing antibodies against SARS-CoV-2; implications in pathogenesis and protective immunity. Biochemical and Biophysical Research Communications, 538, 187-191. https://doi.org/10.1016/j.bbrc.2020.10.108

Cavalcante, J. R., Cardoso-dos-Santos, A. C., Bremm, J.M., Lobo, A. P. Macário, E. M., Oliveira, W.K., \& França, G. V. A. (2020). COVID-19 no Brasil: evolução da epidemia até a semana epidemiológica 20 de 2020. Epidemiologia e Serviços de Saúde [online], 29(4). https://doi.org/10.5123/S167949742020000400010.

Chaimayo, C., Kaewnaphan, B., Tanlieng, N., Athipanyasilp, N., Sirijatuphat, R., Chayakulkeeree, M., Angkasekwinai, N., Sutthent, R., Puangpunngam, N., Tharmviboonsri, T., Pongraweewan, O., Chuthapisith, S., Sirivatanauksorn, Y., Kantakamalakul, W., \& Horthongkham, N. (2020). Rapid SARS-CoV-2 antigen detection assay in comparison with real-time RT-PCR assay for laboratory diagnosis of COVID-19 in Thailand. Virology journal, $17(1), 177$. https://doi.org/10.1186/s12985-020-01452-5

Conselho Regional de Farmácia de São Paulo (CRF-SP) (2020). RDC 377/2020 Em formato de perguntas e respostas, material esclarece dúvidas sobre os testes rápidos para a COVID-19. http://www.crfsp.org.br/noticias/11255-rdc-377-2020.html.

Croda, J. H. R., \& Garcia, L. P. (2020). Resposta imediata da Vigilância em Saúde à epidemia da COVID-19. Epidemiologia e Serviços de Saúde [online]. 2020, 29(1). https://doi.org/10.5123/S1679-49742020000100021

Ercole, F. F., Melo, L. S. de, \& Alcoforado, C. L. G. C. (2014). Revisão integrativa versus revisão sistemática. Revista Mineira de Enfermagem, 18(1), 1-260. DOI: http://www.dx.doi.org/10.5935/1415-2762.20140001

Gao, J., \& Quan, L. (2020). Current Status of Diagnostic Testing for SARS-CoV-2 Infection and Future Developments: A Review. Medical science monitor: international medical journal of experimental and clinical research, 26, e928552. https://doi.org/10.12659/MSM.928552

Garcia, L. P. \& Duarte, E. (2020) Infodemia: excesso de quantidade em detrimento da qualidade das informações sobre a COVID-19. Epidemiologia e Serviços de Saúde [online]., 29(4). https://doi.org/10.1590/S1679-49742020000400019.

Idrovo, Á. J., Moreno-Montoya, J., \& Pinzón-Flórez, C. E. (2020). Desempeño de las pruebas combinadas de IgM e IgG rápidas en la vigilancia ocupacional de COVID-19 en empresas colombianas. Biomedica: revista del Instituto Nacional de Salud, 40(2), 139-147. https://doi.org/10.7705/biomedica.5829

Klein, J., Krüger, L. J., Tobian, F., Gaeddert, M., Lainati, F., Schnitzler, P., Lindner, A. K., Nikolai, O., Knorr, B., Welker, A., de Vos, M., Sacks, J. A., Escadafal, C., Denkinger, C. M., \& Study Team (2021). Head-to-head performance comparison of self-collected nasal versus professional-collected 
nasopharyngeal swab for a WHO-listed SARS-CoV-2 antigen-detecting rapid diagnostic test. Medical microbiology and immunology, 210(4), 181-186. doi: $10.1007 / \mathrm{s} 00430-021-00710-9$

Kweon, O.J., Lim, Y. K., Kim, H. R., Choi, Y., Kim, M. C., Choi, S. H., Chung, J.W., \& Lee, M. K. (2021). Evaluation of rapid SARS-CoV-2 antigen tests, AFIAS COVID-19 Ag and ichroma COVID-19 Ag, with serial nasopharyngeal specimens from COVID-19 patients. PloS one, 16(4), e0249972. https://doi.org/10.1371/journal.pone.0249972

Lacerda, M. G. da C., Silva-Sampaio, J. P. da, \& Dourado, C.S. de M. E. (2021). Percepção da população sobre o papel do Farmacêutico no contexto da pandemia do novo coronavírus. Research, Society and Development, 10(9), e54310918304. https://doi.org/10.33448/rsd-v10i9.18304

Magno, L., Rossi, T. A., Mendonça-Lima, F. W., Santos, C. C., Campos, G.B., Marques, L. M., Pereira, M., Prado, N.M.BL., \& Dourado, I. (2020). Desafios e propostas para ampliação da testagem e diagnóstico para COVID-19 no Brasil. Ciência \& Saúde Coletiva [online]., 25(9), 3355-3364. https://doi.org/10.1590/1413-81232020259.17812020.

Marwitz K. K. (2021). The pharmacist's active role in combating COVID-19 medication misinformation. Journal of the American Pharmacists Association: JAPhA, 61(2), e71-e74. https://doi.org/10.1016/j.japh.2020.10.022

Merola, Y. L., El-Khatib, S. \& Granjeiro, P. A. (2005). Atenção farmacêutica como instrumento de ensino. Infarma, 17(7/9), 70-72. http://revistas.cff.org.br/?journal=infarma\&page=article\&op=view\&path\%5B $\% 5 \mathrm{D}=263 \&$ path $\% 5 \mathrm{~B} \% 5 \mathrm{D}=252$

Nguyen, E., Owens, C. T, Daniels, T., Boyle, J., \& Robinson, R. F. (2021). Vontade dos Farmacêuticos em Prestar Serviços à Doença do Coronavírus (COVID-19) e as Necessidades de Apoio aos Testes, Gestão e Prevenção do COVID-19. Journal of Community Health, 46 (4), 752-757. https://doi.org/10.1007/s10900-020-00946-1

Oliveira, L. A. dos S. M., Souza, A. M. de, Custódio, V. M., Santos, J. S. D. dos, Castro, L. dos S., Zatta, D. T., Taminato, R. L., \& Abrão, F. Y. (2021). Automedicação no Brasil durante a pandemia da COVID-19 e o papel do profissional farmacêutico, uma revisão sistemática. Research, Society and Development, 10(11), e496101119769. http://dx.doi.org/10.33448/rsd-v10i11.19769

Martins, M. A. P., Medeiros, A. F. de, Almeida, C. D. C de, \& Reis, A. M. M. (2020). Preparedness of pharmacists to respond to the emergency of the COVID-19 pandemic in Brazil: a comprehensive overview. Drugs \& therapy perspectives: for rational drug selection and use, 1-8. https://doi.org/10.1007/s40267-020-00761-7

Passos, M. M. B. dos, Castoldi, V. de M., \& Soler, O. (2021). O papel do farmacêutico na pandemia de COVID-19: Revisão integrativa. Research, Society and Development, 10(6), e27110615809. https://doi.org/10.33448/rsd-v10i6.15809

Prado, N. M. B. L., Carvalho, V. N., Nunes, F. G., Jesus, N. N., Santos, H. L. P. C., Santos, A. M. (2021). Análise da produção científica sobre os serviços farmacêuticos comunitários no enfrentamento da pandemia pelo coronavírus. Saúde em Debate [online], 45(129), 533-547. https://doi.org/10.1590/01031104202112921

Santos, L. A. de O., Campelo, Y. D. M., Beltrão, R. P. L., Mendonça, G. de S., Silva, V. A. da, \& Campelo, V. M. de B. (2021). Análise da taxa de eficácia dos testes sorológicos rápidos para COVID-19 registrados na ANVISA, uma revisão sistemática na literatura. Research, Society and Development, 10(11), e264101119615. https://doi.org/10.33448/rsd-v10i11.19615

Strand, M.A., Bratberg, J., Eukel, H., Hardy, M., \& Williams, C. (2020). Contribuições dos farmacêuticos comunitários para o gerenciamento de doenças durante a pandemia de COVID-19. Prevenção de doenças crônicas, 17, E69. https://doi.org/10.5888/pcd17.200317

Teixeira, F.E., Albuquerque, L. N. L. S., Florencio, S. S. G., Fontenele, M. G. M., Queiroz, A. P. O., Lima, G. A., Figueiredo, L. M., Amorim, S. M. C., \& Barbosa, L. P. (2020). Intervalo de tempo decorrido entre o início dos sintomas e a realização do exame para COVID-19 nas capitais brasileiras, agosto de 2020. Epidemiol. Serv. Saúde [online]., 30(1), e2020788. https://doi.org/10.1590/S1679-4974202100010002

Uebbing, E., Lacroix, M., Bratberg, J., \& Federico, C. (2021). Pharmacists' response during a pandemic: A survey on readiness to test during COVID19. Journal of the American Pharmacists Association: JAPhA, 61(2), e80-e84. https://doi.org/10.1016/j.japh.2020.10.003

Vilela, A., Costa, C. A., Oliveira, S. A., Souza, M., Fiaccadori, F. S., Leles, C. R., \& Costa, N. L. (2021). Validade e confiabilidade dos testes rápidos imunocromatográficos IgM/IgG para o diagnóstico salivar de COVID-19. Doenças orais, 00, 1-9. https://doi.org/10.1111/odi.14059

Yüce, M., Filiztekin, E., \& Özkaya, K. G. (2021). COVID-19 diagnosis-A review of current methods. Biosensors \& bioelectronics, 172, 112752. https://doi.org/10.1016/j.bios.2020.112752 